\title{
The damage and tolerance mechanisms of Phaffia rhodozyma mutant strain MK19 grown at $28{ }^{\circ} \mathrm{C}$
}

Li-Li Miao ${ }^{1 *} \mathbb{B}$, Shuang $\mathrm{Chi}^{2}$, Ting-Ting Hou' ${ }^{1}$, Zhi-Pei Liu ${ }^{1}$ and Ying $\mathrm{Li}^{2}$

\begin{abstract}
Background: Phaffia rhodozyma has many desirable properties for astaxanthin production, including rapid heterotrophic metabolism and high cell densities in fermenter culture. The low optimal temperature range $\left(17-21^{\circ} \mathrm{C}\right)$ for cell growth and astaxanthin synthesis in this species presents an obstacle to efficient industrial-scale astaxanthin production. The inhibition mechanism of cell growth at $>21^{\circ} \mathrm{C}$ in P. rhodozyma have not been investigated.
\end{abstract}

Results: MK19, a mutant $P$. rhodozyma strain grows well at moderate temperatures, its cell growth was also inhibited at $28^{\circ} \mathrm{C}$, but such inhibition was mitigated, and low biomass $6 \mathrm{~g} / \mathrm{L}$ was obtained after $100 \mathrm{~h}$ culture. Transcriptome analysis indicated that low biomass at $28^{\circ} \mathrm{C}$ resulted from strong suppression of DNA and RNA synthesis in MK19. Growth inhibition at $28^{\circ} \mathrm{C}$ was due to cell membrane damage with a characteristic of low mRNA content of fatty acid (f.a.) pathway transcripts (acc, fas 1, fas2), and consequent low f.a. content. Thinning of cell wall and low mannose content (leading to loss of cell wall integrity) also contributed to reduced cell growth at $28{ }^{\circ} \mathrm{C}$ in MK19. Levels of astaxanthin and ergosterol, two end-products of isoprenoid biosynthesis (a shunt pathway of f.a. biosynthesis), reached $2000 \mathrm{\mu g} / \mathrm{g}$ and $7500 \mathrm{\mu g} / \mathrm{g}$ respectively; 2-fold higher than levels at 21 or $25^{\circ} \mathrm{C}$. Abundance of ergosterol, an important cell membrane component, compensated for lack of f.a., making possible the biomass production of $6 \mathrm{~g} / \mathrm{L}$ for MK19 at $28^{\circ} \mathrm{C}$.

Conclusions: Inhibition of growth of P. rhodozyma at $28^{\circ} \mathrm{C}$ results from blocking of DNA, RNA, f.a., and cell wall biosynthesis. In MK19, abundant ergosterol made possible biomass production $6 \mathrm{~g} / \mathrm{L}$ at $28{ }^{\circ} \mathrm{C}$. Significant accumulation of astaxanthin and ergosterol indicated an active MVA pathway in MK19 at $28^{\circ} \mathrm{C}$. Strengthening of the MVA pathway can be a feasible metabolic engineering approach for enhancement of astaxanthin synthesis in P. rhodozyma. The present findings provide useful mechanistic insights regarding adaptation of P. rhodozyma to $28^{\circ} \mathrm{C}$, and improved understanding of feasible metabolic engineering techniques for industrial scale astaxanthin production by this economically important yeast species.

Keywords: Phaffia rhodozyma, Moderate-temperature strain, Astaxanthin, Fatty acid, Mevalonate pathway

*Correspondence: miaoll@im.ac.cn

1 State Key Laboratory of Microbial Resources, Institute of Microbiology, Chinese Academy of Sciences, Beijing 100101, People's Republic of China

Full list of author information is available at the end of the article

\section{Background}

Reactive oxygen species (ROS), which are generated in both biochemical and photochemical systems [1], cause cell damage by oxidizing biomolecules such as DNA, proteins, and lipids. Astaxanthin, an orange-red carotenoid pigment, acts as a protective agent against the effects of oxidative damage to cells in vivo $[2,3]$. The antioxidant activity of astaxanthin is 100 - to 500 -fold greater than 
that of vitamin E [4-8]. Astaxanthin from dietary sources is responsible for the orange-red coloration of salmon, lobster, and other seafood species, which cannot synthesize the compound de novo. Astaxanthin, particularly that from natural sources, is utilized extensively in the food, aquaculture, cosmetic, and pharmaceutical industries because of its distinctive coloration and antioxidant properties [1, 9-12].

Phaffia rhodozyma (sexual form: Xanthophyllomyces dendrorhous), a carotenoid-synthesizing yeast having astaxanthin as the main pigment, is the most promising and economical natural source of astaxanthin and has great industrial potential for astaxanthin fermentation $[13,14]$. P. rhodozyma was initially isolated from exudates of trees in isolated locations in Japan and the West Coast of North America. Because its native environment is fairly cold, P. rhodozyma is a psychrophilic (low temperature preferring) species. Both cell growth and astaxanthin biosynthesis in P. rhodozyma are inhibited by high temperatures [15]. The optimal temperature range for these processes is between 17 and $21^{\circ} \mathrm{C}$, and this fact presents an obstacle to industrial production of astaxanthin [15].

Astaxanthin and ergosterol are isoprenoid compounds sharing the conserved mevalonate (MVA) pathway in $P$. rhodozyma [16]. All isoprenoid compounds are based on the C5 isoprene unit. In the initial step of the MVA pathway, two molecules of acetyl-CoA (which is also a substrate of the fatty acid synthetic pathway) undergo condensation to yield acetoacetyl-CoA, which is then converted to MVA, catalyzed by the hmgs and hmgr gene products. MVA is then transferred to farnesyl pyrophosphate (FPP) through a series of condensation steps catalyzed by $m v k, m p d$, $i d i$, and $f p s$-encoded enzymes. This process is collectively termed the MVA pathway because of the importance of the metabolite MVA. FPP undergoes reduction catalyzed by two specific enzymes, encoded by sqs [17] and $c r t$ E, giving rise respectively to ergosterol and astaxanthin.

Formation of phytoene from geranylgeranyl diphosphate (GGPP) is catalyzed by phytoene- $\beta$-carotene synthase (encoded by $p b s$ ), a bifunctional enzyme that also displays lycopene cyclase function in P. rhodozyma [18, 19]. Lycopene is synthesized from phytoene through four subsequent dehydration steps catalyzed by the $c r t \mathrm{I}$ gene product $[20]$. $\beta$-carotene is generated by introducing ring structures at both ends of lycopene, also catalyzed by phytoene- $\beta$-carotene synthase [19]. Finally, $\beta$-carotene is hydroxylated and oxidized to astaxanthin by astaxanthin synthase, which is encoded by the single gene ast $[21,22]$.

Numerous studies during the past decade, by our lab and others, have addressed the molecular regulatory mechanisms of cell growth and astaxanthin synthesis in P. rhodozyma [23-28]. However, these mechanisms remain poorly understood; in particular, the regulatory effects of temperature have not been investigated.

In our previous studies, an astaxanthin-overproducing mutant strain of P. rhodozyma termed MK19 that grows well at moderate temperature $\left(25^{\circ} \mathrm{C}\right)$ was generated by 1-methyl-3-nitro-1-nitrosoguanidine (NTG) and Co60 mutagenesis, and its properties were evaluated [23-26]. In the present study, we examined the alterations in cell growth and synthesis of isoprenoids, cell wall, fatty acids, etc. that occur in MK19 during $28^{\circ} \mathrm{C}$ stress, a temperature at which wild-type (WT) $P$. rhodozyma strain JCM9042 is unable to grow. The molecular effect of high temperature $\left(28^{\circ} \mathrm{C}\right)$ on regulation of cell growth and astaxanthin synthesis was investigated through comparison of transcriptional profiling response to 21 and $28{ }^{\circ} \mathrm{C}$ conditions in WT and MK19.

The obtained transcriptome and metabolic data provide new insights into the genetic and physiological traits and tolerance mechanisms of $P$. rhodozyma, and also reveal potential bioprocesses for optimization of industrial-scale cell growth and astaxanthin synthesis.

\section{Results}

Mutant strain MK19 grew at $28^{\circ} \mathrm{C}$, Astaxanthin content was enhanced significantly at $28^{\circ} \mathrm{C}$ in MK19.

In our 2010 study, P. rhodozyma WT strain JCM9042 grew optimally in the temperature range $17-21{ }^{\circ} \mathrm{C}$, more slowly at $25{ }^{\circ} \mathrm{C}$ [23], and did not grow at $28^{\circ} \mathrm{C}$. Moderate-temperature mutant MK19 grew as well at $25^{\circ} \mathrm{C}$ as it did at $21^{\circ} \mathrm{C}$ [23]. In the present study, growth of MK19 were inhibited but not disrupted at temperatures $>25^{\circ} \mathrm{C}$, and biomass production reached $6 \mathrm{~g} / \mathrm{L}$ for $100 \mathrm{~h}$ culture at $28{ }^{\circ} \mathrm{C}$ (Fig. 1a). The temperature resulting in complete suppression of MK19 growth was higher than that for WT.

For WT, astaxanthin synthesis was reduced and cell coloration nearly eliminated at temperatures $>25^{\circ} \mathrm{C}$ [23]. For MK19, in contrast, astaxanthin content at $28{ }^{\circ} \mathrm{C}$ was $>2000 \mu \mathrm{g} / \mathrm{g}$, which was $\sim 2$-fold higher than content at 21 or $25{ }^{\circ} \mathrm{C}$ (Fig. 1b). Astaxanthin volume yield at $28{ }^{\circ} \mathrm{C}$ was low because of limitation of biomass. For MK19, astaxanthin synthesis tolerated a temperature of $28^{\circ} \mathrm{C}$ as well as it did $25^{\circ} \mathrm{C}$. These findings suggest that cell growth and astaxanthin synthesis in P. rhodozyma are controlled by temperature through independent mechanisms.

\section{Transcriptional profiling of MK19 under $28^{\circ} \mathrm{C}$ stress}

We used RNA-Seq to investigate genomic transcription changes in MK19 during response to $28{ }^{\circ} \mathrm{C}$ and the regulatory network activated by $28{ }^{\circ} \mathrm{C}$ stress. Heat shock response (HSR) functions as a molecular chaperone to protect thermally damaged proteins from aggregation, to 

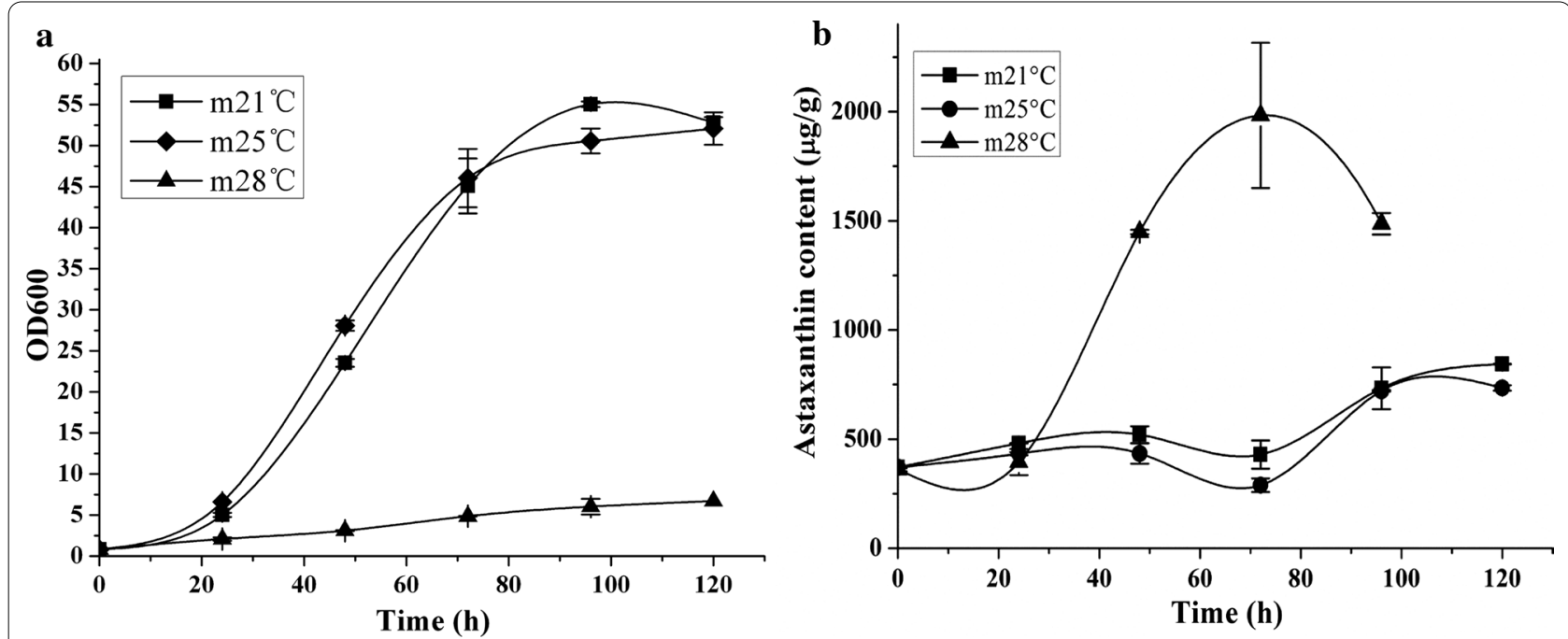

Fig. 1 Cell growth (a) and astaxanthin content (b) of P. rhodozyma strain MK19 at three temperatures as indicated

unfold aggregated proteins, and to refold damaged proteins or target them for efficient degradation. For validation of RNA-Seq data, we performed RT-PCR analysis of 30 genes involved in heat shock-related response, MVA synthetic pathway, and astaxanthin synthetic pathway. For each of these genes, expression was strongly correlated (correlation coefficient 0.86) with RNA-Seq data. Transcripts of twelve heat shock-related genes coding heat shock proteins (HSPs) such as HSP70, HSP30, HSP60, HSP90, HSP78, and HSP104 were notably upregulated under $28{ }^{\circ} \mathrm{C}$ treatment (Table 1). These findings suggest that HSR, which induces a battery of cytoprotective genes that encode HSPs, is an adaptive mechanism in MK19.

Initial functional classification of these differentially expressed genes, using Gene Ontology (GO) and KEGG enrichment, showed that the "purine metabolism" and "pyrimidine metabolism" subsets contained the highest number of genes differentially expressed during MK19 exposure to $28{ }^{\circ} \mathrm{C}$ stress. In the "purine" subset, 24 out of 25 differentially expressed genes showed significant upregulation. In the "pyrimidine" subset, 16 out of 20 differentially expressed genes were upregulated under $28^{\circ} \mathrm{C}$ treatment. Several subsets of genes involved in rRNA and amino acid metabolic processing were also upregulated at $28{ }^{\circ} \mathrm{C}$. Protein contents were $>$ twohold higher under $28{ }^{\circ} \mathrm{C}$ treatment than under $21{ }^{\circ} \mathrm{C}$ treatment throughout the culture period (Fig. 2c), while the RNA synthesis was suppressed at $28^{\circ} \mathrm{C}$ (Fig. 2b).

The genes downregulated under $28{ }^{\circ} \mathrm{C}$ treatment belonged mostly to the "base excision repair" and "fatty acid synthesis" subsets. Seven out of 8 differentially expressed genes in the "base excision repair" subset had extremely low mRNA content at $28^{\circ} \mathrm{C}$, and DNA content was $>$ threefold lower at $28^{\circ} \mathrm{C}$ than at $21^{\circ} \mathrm{C}$ (Fig. 2a). These findings indicate that the low biomass of MK19 at $28{ }^{\circ} \mathrm{C}$ was due to strong suppression of DNA and RNA metabolism.

\section{MK19 cell membrane was damaged at $28^{\circ} \mathrm{C}$}

Biological membranes function as permeable or semipermeable barriers and play key roles in a variety of physiological processes. Maintenance of proper membrane function depends on a precise balance of various lipid species. The biosynthetic pathway of fatty acids (f.a.), essential component of cell membranes, competes with the astaxanthin biosynthetic pathway for the precursor acetyl coenzyme A. Synthesis of f.a., particularly 18:0, 16:0, and 18:1 f.a., was significantly lower at $28^{\circ} \mathrm{C}$ than $21^{\circ} \mathrm{C}$ (Fig. 3). These f.a. species declined steadily throughout the culture period, particularly after $48 \mathrm{~h}$. Total f.a. content at $28{ }^{\circ} \mathrm{C}$ was $\sim 50 \%$ of that detected at $21{ }^{\circ} \mathrm{C}$ treatment (Fig. 3a). 18:1 is the most abundant f.a. species in P. rhodozyma (Fig. 3d), and the inhibitory effect of temperature on f.a. synthesis is based mainly on control of 18:1 synthesis. These findings indicate that reduced biomass of $P$. rhodozyma mutant strain MK19 is due in part to deficiency of f.a., mainly 18:1.

Ergosterol synthesis shares with carotenoid synthesis the initial biosynthetic steps. Changes in sterol composition are associated with enhanced thermotolerance in yeast [29]. WT and MK19 did not show notable differences in ergosterol content at 21 vs. $25{ }^{\circ} \mathrm{C}$. However, astaxanthin content in WT was lower at 25 than at $21{ }^{\circ} \mathrm{C}$ [23]. Regulation of terpenoids and sterols by temperature is evidently based on different 
Table 1 Fold expression changes of HSP, f.a., etc. related genes at 28 vs. $21^{\circ} \mathrm{C}$, based on RT-PCR and RNA-Seq analyses

\begin{tabular}{|c|c|c|c|c|}
\hline & Gene & Function & $\begin{array}{l}\text { RNA-Seq: fold-change } \\
28 / 21^{\circ} \mathrm{C}\end{array}$ & $\begin{array}{l}\text { RT-PCR: } \\
\text { fold- } \\
\text { change } \\
28 / 21^{\circ} \mathrm{C}\end{array}$ \\
\hline 1 & comp12727_c0 & HSP & 1.75 & 1.93 \\
\hline 2 & comp13502_c0 & HSP homolog pss 1 & 16.16 & 3.87 \\
\hline 3 & comp12521_c0 & Dnas family & 1.25 & -1.29 \\
\hline 4 & comp11731_c2 & $\mathrm{HSP}$ & 2.25 & 8.65 \\
\hline 5 & comp11698_c0 & Stress-induced protein STI1 & 2.63 & 2.33 \\
\hline 6 & comp12783_c0 & HSP104 & 2.58 & 4.35 \\
\hline 7 & comp12308_c0 & HSP90 & 12.06 & 3.60 \\
\hline 8 & comp11869_c0 & HSP60 & 2.77 & 2.71 \\
\hline 9 & comp12396_c0 & HSP78 & 2.97 & 4.50 \\
\hline 10 & comp10325_c0 & HSP SSB & 2.45 & 2.23 \\
\hline 11 & comp11696_c0 & hsp70-like protein & 3.74 & 3.65 \\
\hline 12 & comp12989_c0 & HSP70 & 5.66 & N.D. \\
\hline 13 & comp13599_c0 & FAS2 & 0.29 & N.D. \\
\hline 14 & comp13900_c0 & FAS1 & 0.40 & N.D. \\
\hline 15 & comp13834_c0 & ACC1, acetyl-CoA carboxylase & 0.25 & N.D. \\
\hline 16 & comp11956_c0 & f.a.-2 hydroxylase & 0.48 & N.D. \\
\hline 17 & comp12194_c0 & f.a. desaturase & 0.32 & N.D. \\
\hline 18 & comp10129_c0 & WSC domain-containing protein & 0.03 & N.D. \\
\hline 19 & comp10153_c0 & WSC & 1.80 & N.D. \\
\hline 20 & comp10598_c1 & WSC domain-containing protein & 0.18 & N.D. \\
\hline 21 & comp10909_c0 & Related to WSC2 glucoamylase III & 0.77 & N.D. \\
\hline 22 & comp10944_c0 & WSC domain-containing protein & 0.03 & N.D. \\
\hline 23 & comp11101_c1 & WSC & 1.52 & N.D. \\
\hline 24 & comp11381_c0 & WSC domain-containing protein & 0.02 & N.D. \\
\hline 25 & comp11733_c0 & WSC & 0.30 & N.D. \\
\hline 26 & comp12382_c1 & WSC-domain-containing protein & 0.04 & N.D. \\
\hline 27 & comp12404_c0 & WSC & 0.15 & N.D. \\
\hline 28 & comp12789_c0 & WSC & 0.82 & N.D. \\
\hline 29 & comp12838_c0 & WSC & 0.11 & N.D. \\
\hline 30 & comp11864_c1 & Alpha-1,3-mannosyltransferase CMT1 & 2.82 & N.D. \\
\hline 31 & comp12286_c0 & Glycosyltransferase family 22 protein & 3.88 & N.D. \\
\hline 32 & comp12082_c1 & Alpha-1,6-mannosyltransferase & 0.53 & N.D. \\
\hline 33 & comp11585_c0 & Glycosyltransferase family 22 protein & 1.95 & N.D. \\
\hline 34 & comp13450_c0 & 1,3-beta-glucanosyltransferase & 0.45 & N.D. \\
\hline 35 & comp11848_c1 & Endo-1,3(4)-beta-glucanase & 0.27 & N.D. \\
\hline 36 & comp11848_c2 & Endo-1,3(4)-beta-glucanase & 0.31 & N.D. \\
\hline 37 & comp11853_c0 & Endo-1,3(4)-beta-glucanase & 2.89 & N.D. \\
\hline 38 & comp12961_c0 & Glucan endo-1,3-alpha-glucosidase agn 1 & 0.33 & N.D. \\
\hline 39 & comp10598_c0 & Glycoside hydrolase family 71 protein & 0.14 & N.D. \\
\hline 40 & comp13745_c1 & Chitin deacetylase & 4.50 & N.D. \\
\hline 41 & comp14086_c0 & Glycosyltransferase family 2 protein & 2.41 & N.D. \\
\hline 42 & comp12056_c0 & Chitin synthase 1 & 1.75 & N.D. \\
\hline 43 & comp12623_c0 & Glycosyltransferase family 2 protein & 1.99 & N.D. \\
\hline 44 & comp13627_c0 & Glycosyltransferase family 2 protein & 2.2 & N.D. \\
\hline 45 & comp13980_c0 & Chitin synthase 6 & 2.2 & N.D. \\
\hline 46 & comp11755_c0 & HMG-CoA synthase A & 0.80 & 1.39 \\
\hline 47 & comp13410_c0 & HMG-CoA reductase & 1.03 & 1.08 \\
\hline 48 & comp13164_c0 & FPP synthase & 1.12 & 1.50 \\
\hline 49 & comp10042_c0 & IPP isomerase & 0.87 & 2.78 \\
\hline
\end{tabular}


Table 1 (continued)

\section{N.D. not detected}

No. 1-12: HSP genes. No. 13-17: f.a. biosynthetic pathway genes. No. 18-29: WSC genes. No. 30-33: mannan biosynthetic pathway genes. No. 34-39: glucan biosynthetic pathway genes. No. 40-45: chitin biosynthetic pathway genes.No. 46-49: MVA pathway genes
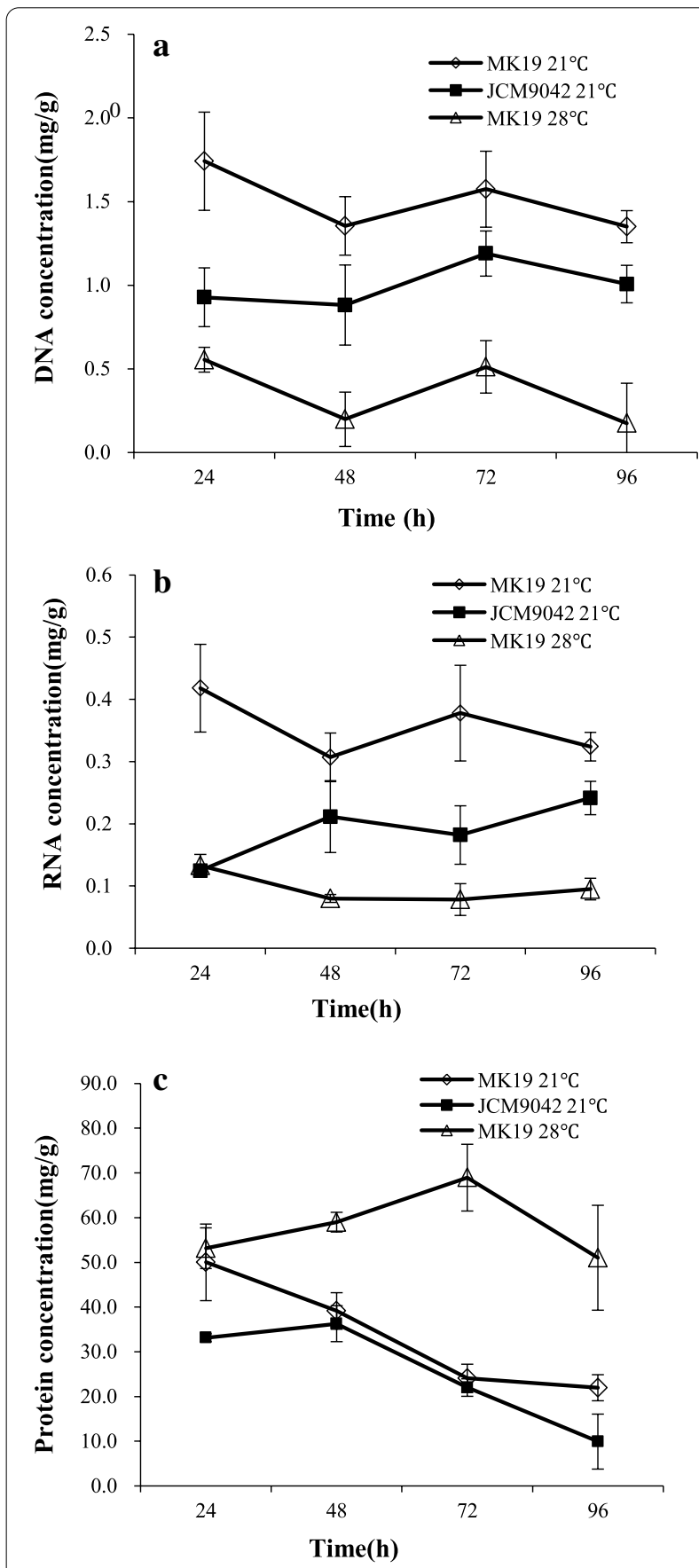

Fig. 2 Concentrations of DNA (a), RNA (b), and protein (c) in MK19 grown at 21 and $28^{\circ} \mathrm{C}$, and in strain JCM9042 (WT) grown at $21^{\circ} \mathrm{C}$ mechanisms; only terpenoid synthesis was inhibited specifically by $25^{\circ} \mathrm{C}$ in WT $P$. rhodozyma. In contrast, ergosterol content was significantly different at $28{ }^{\circ} \mathrm{C}$ in comparison with $21{ }^{\circ} \mathrm{C}$; that of MK19 was nearly twofold higher at $28{ }^{\circ} \mathrm{C}$ than at 25 or $21^{\circ} \mathrm{C}$ (Fig. $4 \mathrm{~b}$ ). Astaxanthin synthesis was also higher at $28{ }^{\circ} \mathrm{C}$ in MK19 (Fig. 1b). Ergosterol is an important structural enhancement (strengthening) component of cell membranes. Promotion of ergosterol synthesis in MK19 compensated the reducing of fatty acids and mitigates inhibition of cell growth and helps modulate adaptive response to $28{ }^{\circ} \mathrm{C}$ stress. High temperature apparently fosters sterol and terpenoid metabolic fluxes simultaneously in MK19.

According to RNA-Seq analysis, genes involved in f.a. synthetic pathway had very low mRNA content at $28^{\circ} \mathrm{C}$. mRNA content at $28{ }^{\circ} \mathrm{C}$ for $\operatorname{acc} 1$ (comp13834_c0), the first key regulatory gene in f.a. synthetic pathway [26], was $\sim 25 \%$ relative to $21{ }^{\circ} \mathrm{C}$. Low transcription of acc 1 in MK19 at $28{ }^{\circ} \mathrm{C}$ accounts for the low f.a. content and to some degree the low biomass at this temperature. Besides acc1, levels of fas 1 (comp13900_c0), fas 2 (comp13599_ c0), f.a.-2 hydroxylase (comp11956_c0), and f.a. desaturase (comp12194_c0) were reduced at $28{ }^{\circ} \mathrm{C}$ (Table 1 , No. 13-16). Metabolic and mRNA data, taken together, indicate that f.a. synthetic pathway was hindered by $28^{\circ} \mathrm{C}$ stress, and that growth of $P$. rhodozyma at $28^{\circ} \mathrm{C}$ requires an adequate amount of f.a. Therefore, modification of acc, fas 1 , and fas 2 expression in future studies could potentially enhance cell growth at $28{ }^{\circ} \mathrm{C}$. $s q s$ is the first key regulatory gene in ergosterol synthetic pathway [26]. sqs and other genes in this pathway showed no notable change in mRNA content. In contrast to mRNA content, ergosterol content of MK19 was 2-fold higher at $28{ }^{\circ} \mathrm{C}$ than at 21 or $25^{\circ} \mathrm{C}$. Increased content of ergosterol may compensate in part for loss of f.a., and promote survival of MK19 at $28^{\circ} \mathrm{C}$.

Another relevant factor is the competition among carotenoids, ergosterol, f.a., and other macromolecules for acetyl-CoA and FPP. When f.a. synthesis was suppressed by high temperature in MK19, a large amount of the intermediate acetyl-CoA was likely accumulated and transferred to isoprenoid biosynthetic pathway through upstream MVA pathway, with the result that astaxanthin and ergosterol content were 2 -fold higher at $28{ }^{\circ} \mathrm{C}$ than 


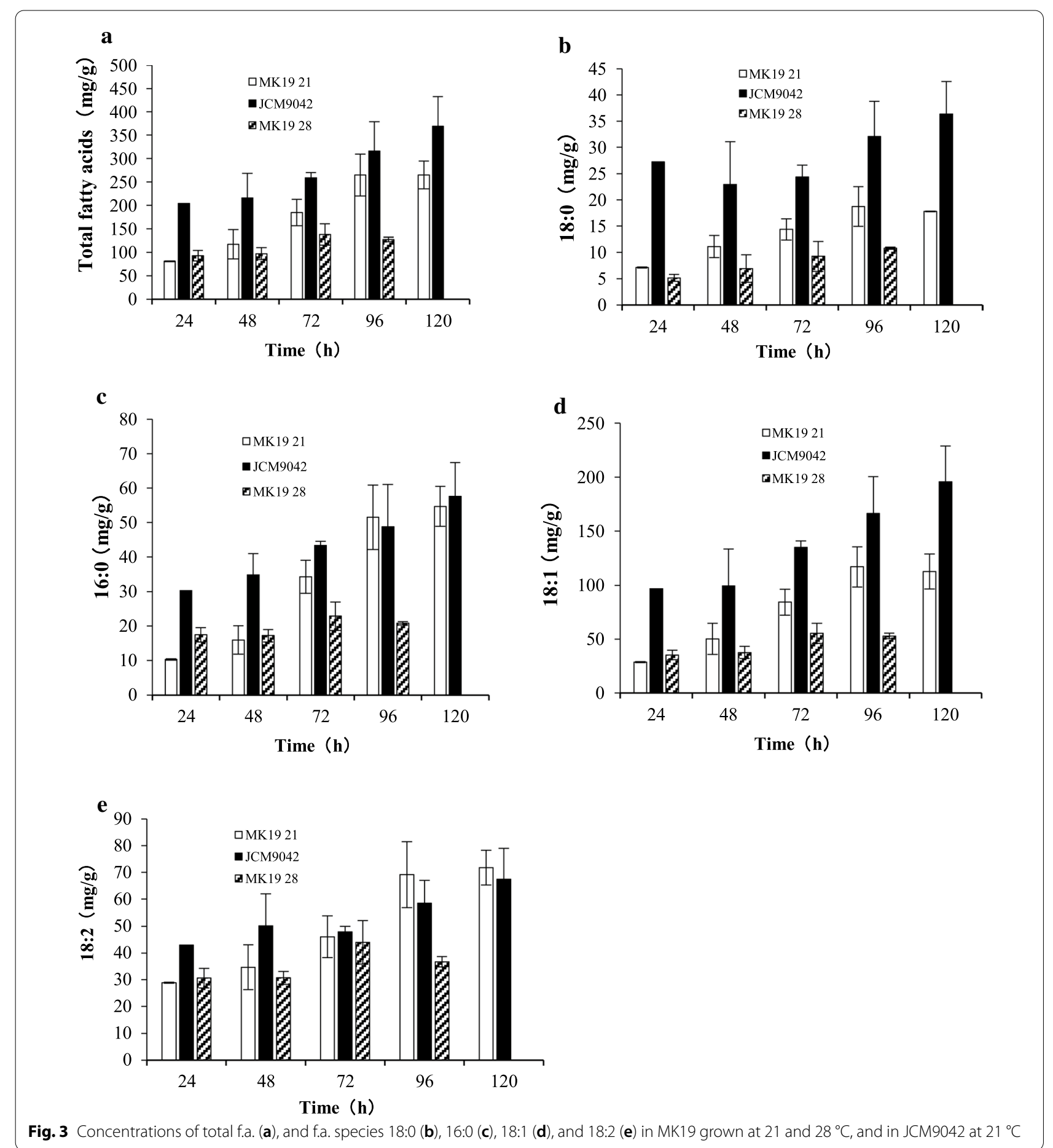

at lower temperatures. This observation is consistent with the conclusion from our 2011 study that strengthening of MVA pathway in MK19 is a promising metabolic engineering approach for enhancement of astaxanthin production [24]. In the present study, carotenoid content was inversely correlated with f.a. biosynthesis.

\section{Suppression of cell wall metabolites contributes to reduced} cell growth at $28^{\circ} \mathrm{C}$

The fungal cell wall plays an essential role in maintenance of cell shape, integrity, and function. It contacts and interacts with the extracellular environment, and can trigger various physiological processes to adapt to changing 

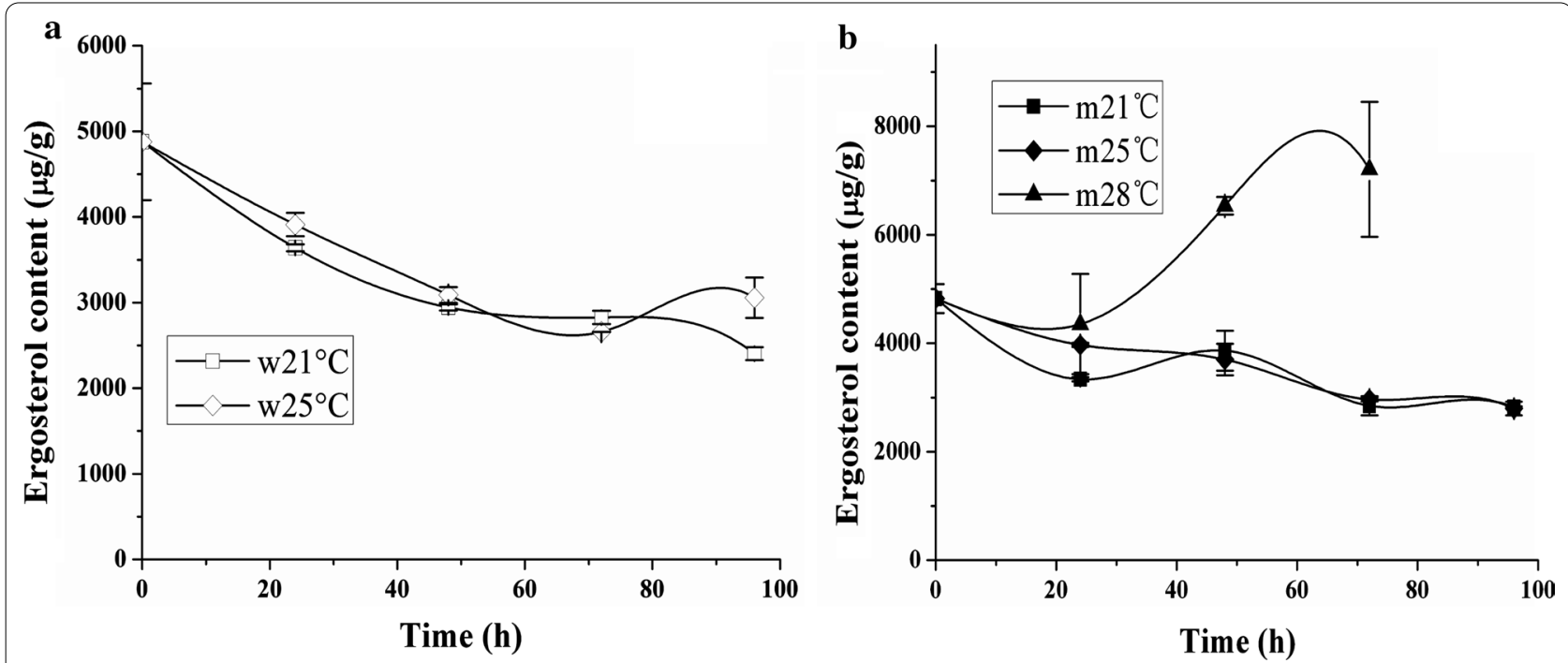

Fig. 4 Ergosterol contents of JCM9042 (a) and MK19 (b) grown at three temperatures

circumstances. WSC1, a stress circumstance sensory protein located in cell membrane, is used as a probe for cell wall functioning in fungi. Increasing evidence indicates that defects in wsc1 and other wsc family genes in yeast contribute to increased sensitivity to temperature or other stress factors, and may lead to cell lysis [30, $31]$. In the present study, none of the wsc genes showed mRNA increase. Under $28{ }^{\circ} \mathrm{C}$ treatment of MK19, 8 out of $12 \mathrm{Wsc}$ domain-containing proteins showed extremely low mRNA, one (comp11733_c0) showed 3.5-fold downregulation, and others showed 8- to 32-fold downregulation (Table 1, No. 18-29). These findings suggest that temperature sensitivity in MK19 is related to low mRNA level of wsc genes, and that high temperature suppresses cell growth through its effect on cell wall synthesis.

MK19 cell wall structure varied considerably as a function of temperature. Total cell wall thickness was $0.46 \pm 0.11 \mu \mathrm{m}$ at $21{ }^{\circ} \mathrm{C}$ and $0.38 \pm 0.07 \mu \mathrm{m}$ at $28{ }^{\circ} \mathrm{C}$. In particular, thickness of the mannan layer at $28{ }^{\circ} \mathrm{C}$ $(0.15 \pm 0.04 \mu \mathrm{m})$ was only about half that at $21{ }^{\circ} \mathrm{C}$ $(0.26 \pm 0.08 \mu \mathrm{m})$. Thickness of the chitin/ glucan layer increased $0.12 \mu \mathrm{m}$ at $28{ }^{\circ} \mathrm{C}$ (Fig. 5; Table 2). A recent study by H.A. Kang's group suggests that accumulation of mannan in cell wall enhances stress resistance [31]. In MK19 cell wall outer layer, mannose component was notably reduced at $28{ }^{\circ} \mathrm{C}$ (Figs. 5 and 6; Table 2), resulting in disruption of cell wall integrity (CWI), and inhibition of cell growth. In contrast, $28{ }^{\circ} \mathrm{C}$ treatment resulted in increased expression of genes associated with mannan component biogenesis; i.e., the genes encoding $\alpha-1,3$-mannosyltransferase (comp11864_c1), $\alpha-1,2$-mannosyltransferase (comp12286_ $\mathrm{c} 0$ ), and $\alpha$-1,6-mannosyltransferase (comp11585_c0).
MK19 glucan levels were higher at $28^{\circ} \mathrm{C}$, consistent with previous findings that higher $\beta$-glucan levels are associated with greater stress resistance in yeast strains [32]. In our study, higher glucan level promoted MK19 survival at $28{ }^{\circ} \mathrm{C}$. In MK19 at $28{ }^{\circ} \mathrm{C}$, mRNAs of most glucan biosynthesis-related genes were downregulated; these included $\beta$-1,3-glucanosyltransferase (comp13450_c0), $\beta$-1,3-glucanase (comp11848-co, comp11848-c1), and endo-1,3- $\alpha$-glucanase agn1 (comp12961_c0, comp10598_ $\mathrm{c} 0$ ). Yeast cells sometimes deposit more chitin in lateral walls to compensate for compromised cell integrity [32]. In our study, genes that encode enzymes involved in chitin synthesis were upregulated; these include chitin deacetylase (comp13745), chitin synthase CHS1 (comp12056, comp13627), chitin synthase CHS2 (comp12623, comp13980), and chitin synthase CHS2,1,8 (comp14086). Regulatory patterns for glucans and those for mannan were quite different.

\section{Expression of MVA pathway and astaxanthin pathway genes}

The MVA pathway includes the early steps of terpenoid synthesis. hmgr and hmgs, the key regulatory genes in the terpenoid pathway in eukaryotes, are subject to feedback control at multiple levels; e.g., transcriptional, translational, and enzyme stability [33]. RNA-Seq analysis of MK19 showed no notable expression changes for genes upstream of MVA pathway at $21 \mathrm{vs.} 28^{\circ} \mathrm{C}$. The same was true for RT-PCR analysis, except in the case of $i d i$, the gene that encodes the enzyme isopentenyl diphosphate (IDP) isomerase. idi transcription was induced at 25 and $28{ }^{\circ} \mathrm{C}$ in both WT and MK19. For MK19, the maximal increase at $28^{\circ} \mathrm{C}$ was $\sim 10$-fold higher than at $21^{\circ} \mathrm{C}$ (data 

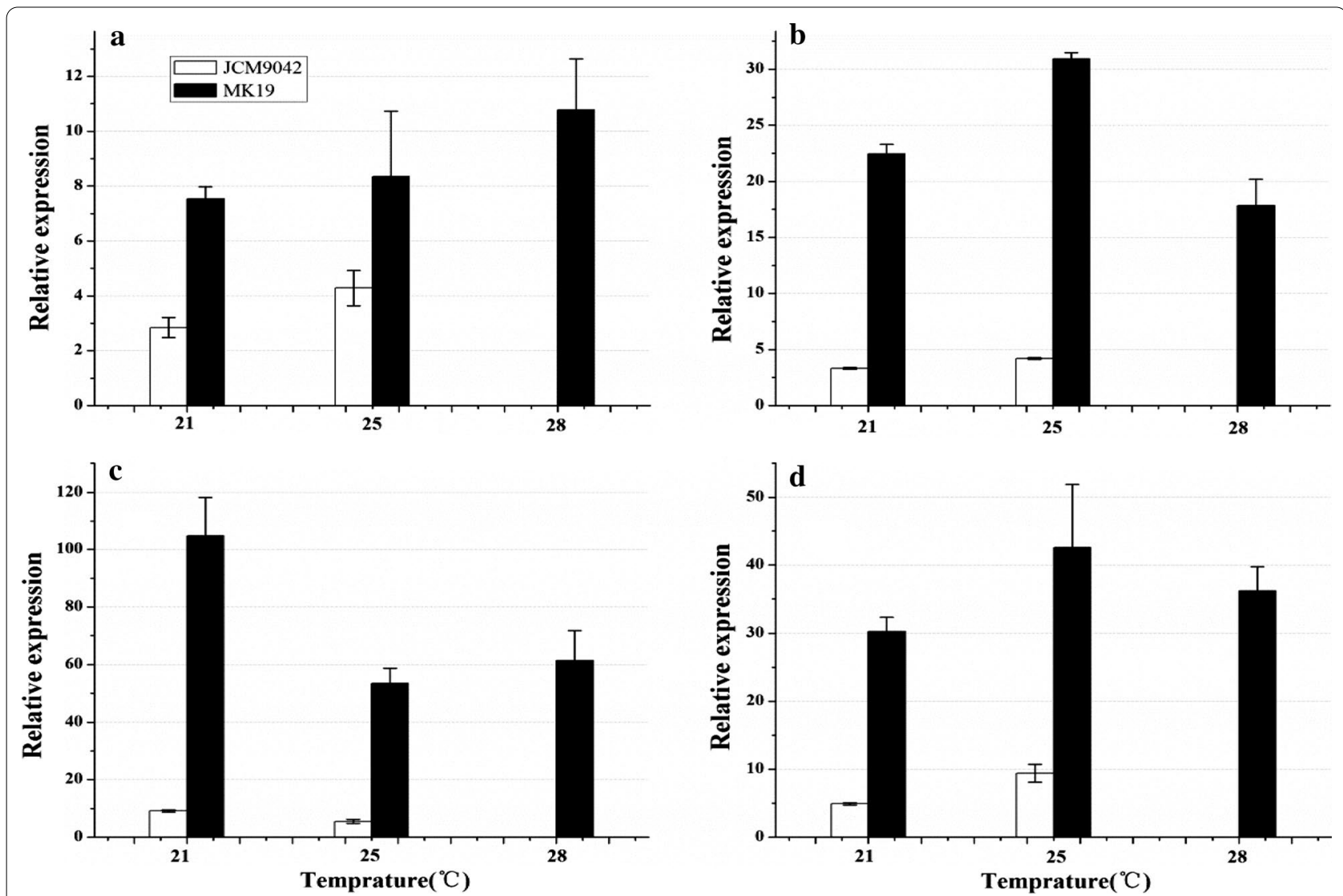

Fig. 5 Cellular morphology following culture of JCM9042 grown at $21{ }^{\circ} \mathrm{C}(\mathbf{a})$, and of MK19 grown at $21^{\circ} \mathrm{C}(\mathbf{b})$ and $28^{\circ} \mathrm{C}(\mathbf{c})$

not shown). hmgs and hmgr expression was not inhibited at $28{ }^{\circ} \mathrm{C}$ in MK19, despite the fact that ergosterol content was 2 -fold higher at this temperature than at 21 or $25^{\circ} \mathrm{C}$. hmgs expression was enhanced at temperatures $>21^{\circ} \mathrm{C}$ in both WT and MK19.

Relative expression of carotenoid pathway genes at these three temperatures were compared between WT and MK19. The results (Fig. 7) were consistent with those from RNA-Seq analysis. Expression of $p b s$ and ast did not differ notably between three temperatures in WT and MK19. crtE expression was slightly higher at $28{ }^{\circ} \mathrm{C}$, whereas $\operatorname{crtI}$ expression was reduced $\sim 1.5$-fold at temperatures $>21^{\circ} \mathrm{C}$ in both WT and MK19.

The inhibitory effect of high temperature on astaxanthin synthesis was exerted mainly at the four dehydrogenation steps leading from phytoene to lycopene in both WT and MK19. Reduced mRNA content of crtI was an important cause of astaxanthin inhibition at temperatures $>25{ }^{\circ} \mathrm{C}$. crtI mRNA level was $>10$-fold higher in MK19 than in WT. This level in MK19 was reduced 1.5fold at 25 and $28{ }^{\circ} \mathrm{C}$, but was still sufficient to counteract the inhibitory effect of higher temperature and lead to efficient transfer in the four from phytoene-to-lycopene dehydrogenation steps. Therefore, metabolic engineering of these steps, e.g., overexpression of $c r t \mathrm{I}$, is a feasible and promising method for enhancement of astaxanthin content in WT or other P. rhodozyma strains.

\section{Discussion}

The yeast Phaffia rhodozyma has great potential for industrial-scale astaxanthin production, and has been a subject of great biotechnological interest for several decades $[13,14]$. It is a psychrophilic (low temperature preferring) species whose native habitats in Japan and the North American West Coast are isolated and fairly cold. Applicability of WT P. rhodozyma in industrial production is limited because its temperature range for optimal cell growth and astaxanthin biosynthesis is $17-21^{\circ} \mathrm{C}$. We previously established an astaxanthin-overproducing, moderate-temperature mutant strain of $P$. rhodozyma, termed MK19, by NTG and $\mathrm{Co}^{60}$ mutagenesis $[23,24]$. The regulatory effects of temperature on cell growth and astaxanthin synthesis of $P$. rhodozyma have not been investigated, and our knowledge of the molecular regulatory mechanisms in general is quite fragmentary. 

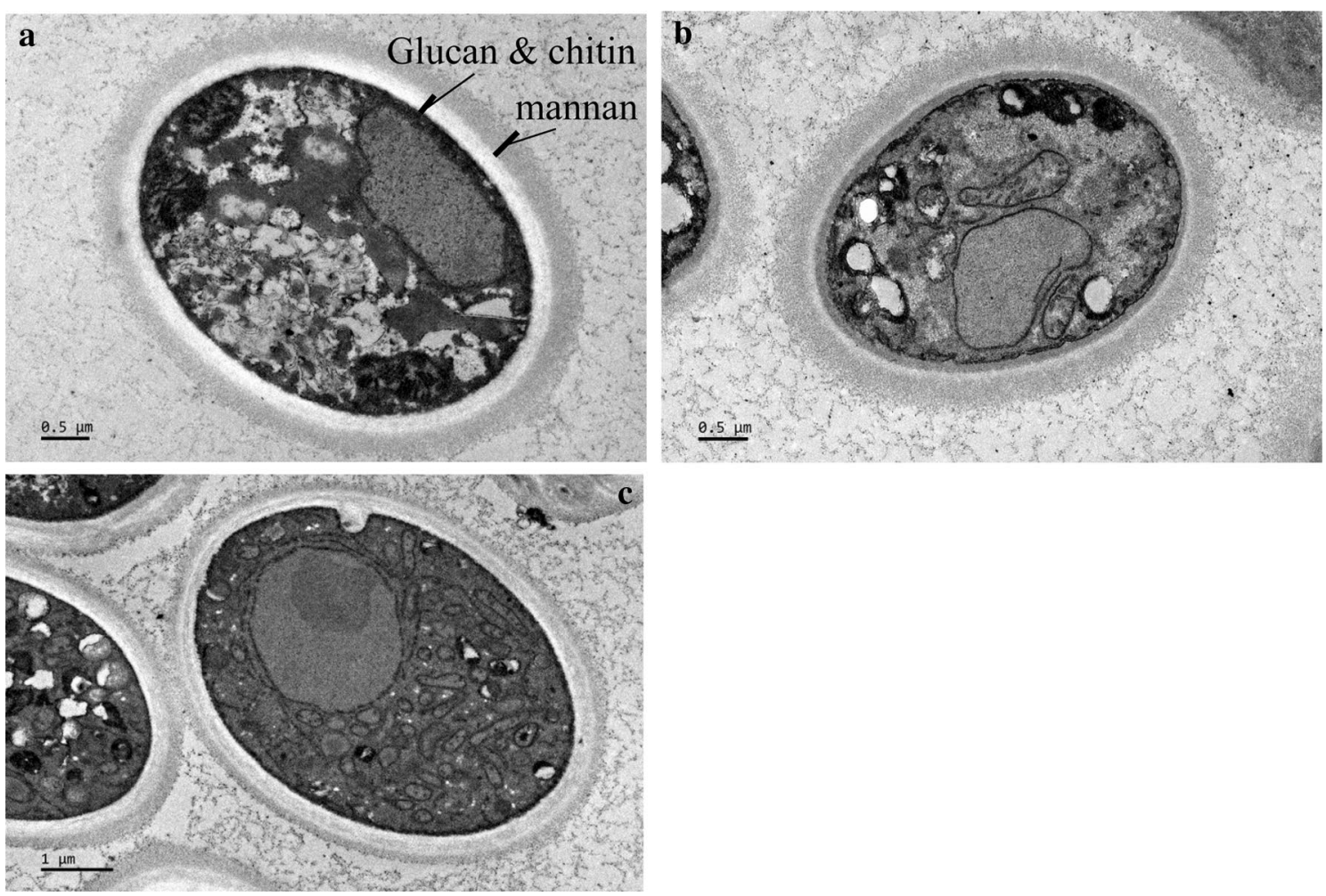

Fig. 6 Proportions of three cell wall components of JCM9042 at $21{ }^{\circ} \mathrm{C}$ grown and of MK19 grown at 21 and $28^{\circ} \mathrm{C}$

Table 2 Cell wall thickness comparisons for MK19 grown at 21 and $28^{\circ} \mathrm{C}$, and JCM9042 grown at $21^{\circ} \mathrm{C}$

\begin{tabular}{cccc}
\hline & Total cell wall $(\mu \mathrm{m})$ & $\begin{array}{l}\text { Chitin/ glucan } \\
\text { layer }(\mu \mathrm{m})\end{array}$ & Mannan layer $(\mu \mathrm{m})$ \\
\hline MK19 & & & \\
$21^{\circ} \mathrm{C}$ & $0.46 \pm 0.11$ & $0.18 \pm 0.05$ & $0.26 \pm 0.08$ \\
$28^{\circ} \mathrm{C}$ & $0.38 \pm 0.07$ & $0.24 \pm 0.04$ & $0.15 \pm 0.04$ \\
$\mathrm{JCM} 9042$ & & & \\
$21^{\circ} \mathrm{C}$ & $0.48 \pm 0.13$ & $0.16 \pm 0.05$ & $0.32 \pm 0.08$ \\
\hline
\end{tabular}

We describe here for the first time the biosynthetic and regulatory mechanisms of cell growth and astaxanthin production at high temperature $\left(28^{\circ} \mathrm{C}\right)$ in $P$. rhodozyma. WT strain cannot grow at $28^{\circ} \mathrm{C}$. MK19 biomass production at $28{ }^{\circ} \mathrm{C}$ reached $6 \mathrm{~g} / \mathrm{L}$, which was $80 \%$ less than values at 21 or $25^{\circ} \mathrm{C}$. Our RNA-Seq and metabolic analyses revealed 5 regulatory patterns involving temperature, as follows. (1) Upregulation of genes that encode proteins involved in protein folding and stabilization, including HSPs, rRNA processing, and amino acid synthesis. These genes have high copy numbers, reflecting protein denaturation and misfolding, which may result from $28{ }^{\circ} \mathrm{C}$ stress. The high copy numbers help mitigate such stress

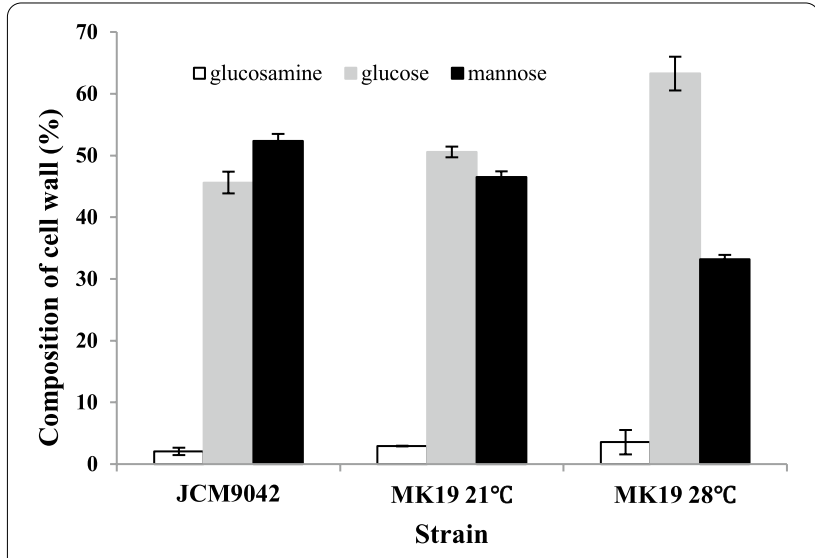

Fig. 7 Relative expression of carotenoid pathway genes (a: crtE; $\mathbf{b}$ : pbs; c: crtl; d: ast) in JCM9042 and MK19 grown at three temperatures

through increased protein synthesis, and refolding and reactivating functions of denatured proteins. (2) DNA metabolism was strongly suppressed at the mRNA level, and low mRNA content accounted for the low viability of MK19 at $28{ }^{\circ} \mathrm{C}$. (3) Inability of WT to grow at $28{ }^{\circ} \mathrm{C}$ was due in part to reduced synthesis of f.a. (a major component) in cell membrane, reflected in low transcriptional 
capacity of key f.a. synthesis genes (acc, fas 1, fas 2 ) and low f.a. content (particularly of 18:1 species). Low biomass of WT at $28{ }^{\circ} \mathrm{C}$ was related to altered content of 18:1 species. (4) High content $(7500 \mu \mathrm{g} / \mathrm{g})$ of ergosterol, a structural enhancement (strengthening) component of cell membrane, compensated in part for the low f.a. content, and explain the relief the growth repression of MK19 at $28{ }^{\circ} \mathrm{C}$. Engineering of the f.a. biosynthetic pathway could potentially convert MK19 or other $P$. rhodozyma strains to mesophilic strains having optimal growth temperature $\sim 28{ }^{\circ} \mathrm{C}$. (5) Fungi have a rigid cell wall that plays an important role in cell growth. Cell wall in $P$. rhodozyma loses integrity at $28^{\circ} \mathrm{C}$ because the outer mannose layer becomes thinner, another reason why WT is unable to grow at this temperature.

Cell wall plasticity and composition depend on active regulation of underlying biosynthetic and restructuring processes. The cell wall integrity (CWI) pathway is a central signaling cascade that is highly conserved in fungi $[30,31]$. CWI pathway is essential for adaptation to a wide variety of cell wall disrupting conditions, including heat stress. Heat shock triggers activation of CWI and
HSP pathways, resulting in global transcriptomic changes in various biosynthetic pathways, including cell wall remodeling enzymes and mannan and glucan biosynthesis. Observed differential expression of genes encoding WSC proteins, f.a., and other cell wall components reflects the essential role of CWI and HSP pathways in adaptation to $28^{\circ} \mathrm{C}$ stress in MK19. A schematic model of candidate processes contributing to adaptive response of MK19 to $28^{\circ} \mathrm{C}$ stress, based on RNA-Seq and metabolic analyses, is presented in Fig. 8.

In summary, regulatory patterns (1) and (4) contributed to tolerance of cell growth, while (2), (3), and (5) accounted for damage of cell growth of MK 19 at $28^{\circ} \mathrm{C}$.

In our 2011 study, astaxanthin content of WT P. rhodozyma was lower at $25^{\circ} \mathrm{C}$ than at $21{ }^{\circ} \mathrm{C}$ whereas ergosterol content was the same at these two temperatures, indicating that astaxanthin and ergosterol are regulated through independent mechanisms [24]. Synthesis of carotenoids (but not of other isoprenoids) was inhibited at $25{ }^{\circ} \mathrm{C}$. crtI mRNA level at $25^{\circ} \mathrm{C}$, which was $\sim 1.5$-fold lower than that at $21^{\circ} \mathrm{C}$, accounted for such inhibition in WT.

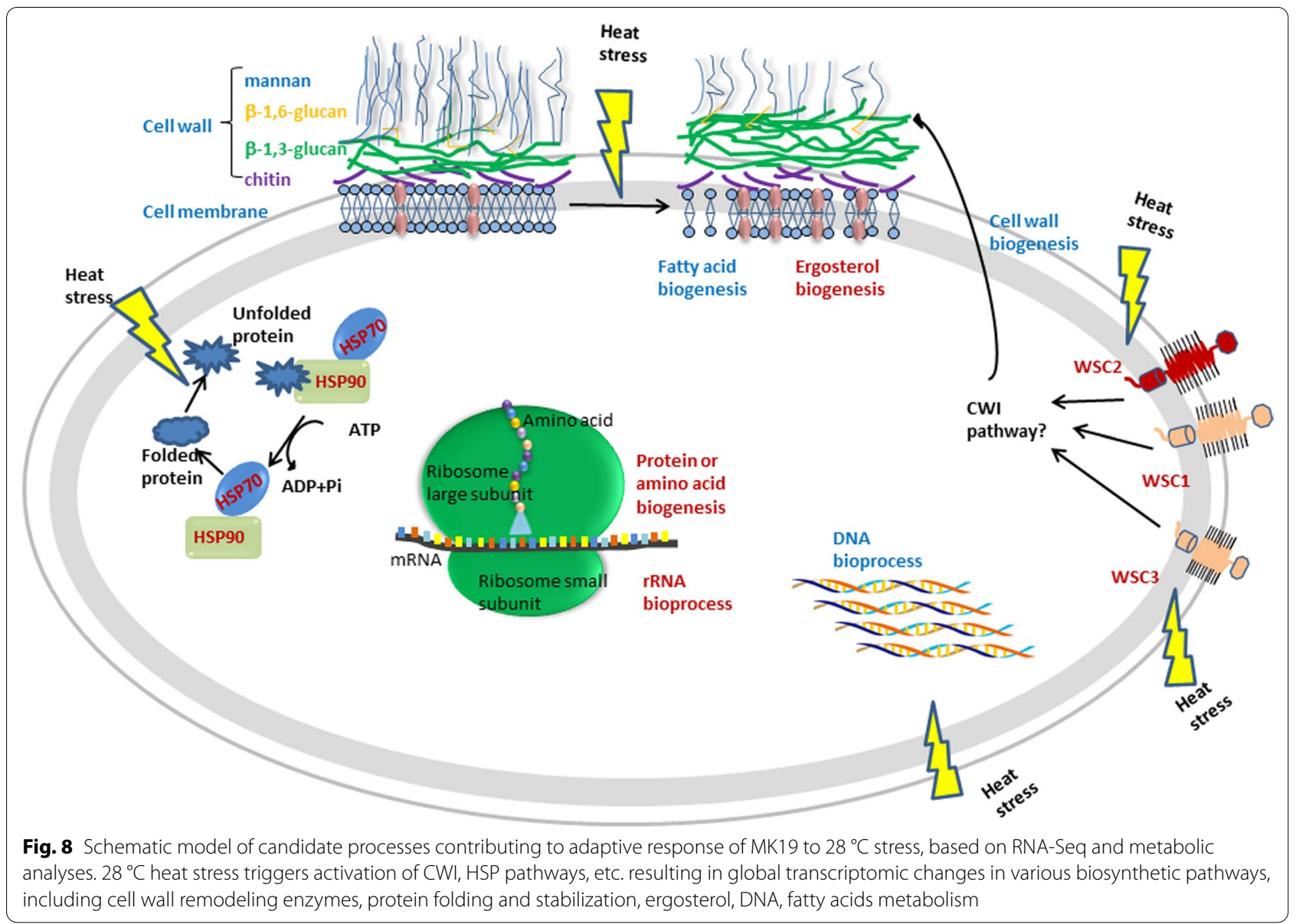


Despite the transcriptional inhibition of $c r t \mathrm{I}$, the high crtI mRNA of MK19 (>10-fold higher than that of WT) was enough and accounted for the high efficiency of astaxanthin synthesis at 25 or $28{ }^{\circ} \mathrm{C}$. Thus, inhibition of astaxanthin synthesis by high temperature in $P$. rhodozyma appears to occur mainly at the conversion step from phytoene to lycopene. Metabolic engineering of this step (e.g., overexpression of $c r t \mathrm{I}$ ) could be a feasible method for increasing astaxanthin content at temperatures $>25^{\circ} \mathrm{C}$ in this species.

Astaxanthin and ergosterol content in MK19 were increased $>$ twofold at $28{ }^{\circ} \mathrm{C}$, in contrast to cell growth, suggesting that isoprenoid biosynthetic pathway (particularly MVA pathway which includes the initial steps of isoprenoid synthesis) was activated at this temperature. There is competition among intermediate compounds of the f.a., astaxanthin, and ergosterol pathways because these macromolecules share common precursors, such as acetyl-CoA, etc. Astaxanthin content is inversely correlated with f.a. synthesis in P. rhodozyma [23]. F.a. synthesis in MK19 was inhibited at $28{ }^{\circ} \mathrm{C}$, resulting in a probable accumulation of acetyl-CoA and other precursors, enhanced activity of MVA pathway, excessive synthesis of ergosterol, and reduction of biomass. Precursors from MVA pathway and F. a. synthesis were also diverted to astaxanthin biosynthesis via activated carotenoid pathway in MK19, resulting in increase of astaxanthin content to $2000 \mu \mathrm{g} / \mathrm{g}$. The present findings, taken together, clearly indicate that strengthening of the MVA pathway is a feasible and efficient metabolic engineering approach for enhancement of astaxanthin synthesis in MK19 or other moderate-temperature strains.

\section{Conclusions}

The inability of growing at $28{ }^{\circ} \mathrm{C}$ in WT P. rhodozyma is due to blocking of DNA, RNA, cell membrane, and cell wall biosynthesis through transcriptional regulation. In the moderate-temperature mutant strain MK19, excessive accumulation of ergosterol, glucan, and protein, at this temperature led to biomass production of $6 \mathrm{~g} / \mathrm{L}$. Precursors, such as acetyl-coA, from impeded f.a. pathway, were diverted to and stimulated both of astaxanthin and ergosterol biosynthesis. Strengthening of the MVA pathway could be a feasible metabolic engineering approach for enhancement of astaxanthin synthesis in MK19 or other moderate-temperature producer strains.

\section{Methods}

\section{Strains and culture conditions}

WT P. rhodozyma strain JCM9042 was from the Institute of Physical and Chemical Research, Japan. MK19, an astaxanthin-overproducing and moderate-temperature mutant strain, was generated and screened by NTG and
$\mathrm{Co}^{60}$ mutagenesis in our laboratory [24]. Both strains were maintained on potato dextrose agar slants at $4{ }^{\circ} \mathrm{C}$.

Seed medium and fermentation medium were prepared as described previously [24]. All experiments were conducted in shaking flask culture in $250 \mathrm{ml}$ flasks containing fixed liquid volume $25 \mathrm{ml}$.

WT and MK19 cells were transferred from $4{ }^{\circ} \mathrm{C}$ slants to fresh slants and maintained at $21-24^{\circ} \mathrm{C}$ for $72 \mathrm{~h}$. Loopfuls of lawn were inoculated in seed medium and incubated at $21-24{ }^{\circ} \mathrm{C}$ for another $72 \mathrm{~h}$. Five percent of the preincubation broth was further inoculated for another $36 \mathrm{~h}$ to produce starter culture. The overall production period of fermentation culture was 4-6 days on a rotary shaker $\left(210 \mathrm{rpm}, 21^{\circ} \mathrm{C}\right)$, with samples taken at 12 or $24 \mathrm{~h}$ intervals. All experiments were performed in triplicate or quadruplicate.

Cell concentrations were estimated by measuring optical density at wavelength $600 \mathrm{~nm}$. Dry weight of cells was determined by centrifuging $35 \mathrm{ml}$ broth at $12,000 \mathrm{rpm}$, rinsing with distilled water, and drying at $85{ }^{\circ} \mathrm{C}$ until attaining constant weight $(\sim 15 \mathrm{~h})$.

\section{Astaxanthin and total ergosterol measurement}

One $\mathrm{ml}$ broth was centrifuged at 12,000 rpm for $1 \mathrm{~min}$ and washed with distilled water. Pellets were mixed with $200 \mu$ dimethyl sulfoxide preheated to $70{ }^{\circ} \mathrm{C}$, stirred, and the mixture was heated in a water bath for $20 \mathrm{~min}$ at $70{ }^{\circ} \mathrm{C}$. Broken cells were extracted with methanol/ dichloromethane (3:1), agitated, and centrifuged at $2000 \mathrm{rpm}$. The supernatant was transferred to another tube. This process was repeated until pellets showed no red color. Astaxanthin and free ergosterol were analyzed quantitatively by HPLC on a C18 column $(250 \times 4.6 \mathrm{~mm} ; 5 \mu \mathrm{m}$; Chuangxintongheng, Beijing): temperature $40{ }^{\circ} \mathrm{C}$, flow rate $1.0 \mathrm{ml} / \mathrm{min}$, wavelength $476 \mathrm{~nm}$ (for astaxanthin) or $280 \mathrm{~nm}$ (for ergosterol). The mobile phase consisted of methanol 97\%/ water 3\%. Astaxanthin and ergosterol were identified based on retention time in comparison with standard astaxanthin (Sigma-Aldrich; Shanghai).

\section{DNA, RNA, protein, fatty acids measurement}

The cell samples were collected by centrifugation $(12,000 \mathrm{rpm}, 2 \mathrm{~min})$ and frozen in liquid nitrogen immediately. then cell lysis were obtained by shattering thoroughly by homogenizer for $5 \mathrm{~min}$, protein samples were collected by centrifugal (12,000 rpm, $20 \mathrm{~min})$ after adding $20 \mathrm{mM}$ PBS buffer (pH 7.0) to cell lysis, protein content of supernatant were determined by Bradford method. The DNA and RNA samples were extracted by HiBind DNA Mini Column and HiBind RNA Mini Column from DNA or RNA extraction kit (Omega, US), after several washing steps, the DNA or RNA was eluted from the column. The DNA, RNA, Protein content were determined 
by Nanodrop 2000 (Thermo), the fatty acid content was determined the same as Miao et al. [23].

\section{Total RNA purification and reverse transcription}

Cells of WT and MK19 in $1 \mathrm{ml}$ broth were harvested by centrifugation (12,000 rpm, $1 \mathrm{~min})$, frozen immediately in liquid nitrogen, and stored at $-70^{\circ} \mathrm{C}$ until processing. RNA extraction was performed using TRIzol Reagent (Invitrogen) as per manufacturer's instructions. Total RNA concentration was determined by spectrophotometry at $260 \mathrm{~nm}$. Aliquots of extracts were subjected to agarose gel electrophoresis to check RNA integrity.

To degrade trace amounts of genomic DNA in RNA preparations, DNase I (Takara Japan) $(1 \mu \mathrm{l} ; 5 \mathrm{U} / \mu \mathrm{l})$ was added to reaction mixture containing $5 \mu \mathrm{g}$ RNA, $4.4 \mu \mathrm{l}$ of $25 \mathrm{mM} \mathrm{MgCl}, 2 \mu \mathrm{l}$ of $10 \times$ buffer (Takara Japan), and DEPC-treated water was added to give total volume $20 \mu \mathrm{l}$. Reaction mixture was incubated for $30 \mathrm{~min}$ at $37^{\circ} \mathrm{C}$ followed by heat denaturation for $15 \mathrm{~min}$ at $65^{\circ} \mathrm{C}$.

RNA sample was heated to $70{ }^{\circ} \mathrm{C}$, and reverse transcription reaction was performed in a final volume of $25 \mu \mathrm{l}$ containing $2 \mu \mathrm{g}$ total RNA, $1 \mu \mathrm{l}$ oligo(dT) primer, $0.5 \mathrm{mM}$ dNTPs, and $200 \mathrm{U}$ M-MLV reverse transcriptase $\mathrm{H}$ minus (Promega). Reaction mixture was incubated for $60 \mathrm{~min}$ at $42^{\circ} \mathrm{C}$, then heated to $65^{\circ} \mathrm{C}$ for $15 \mathrm{~min}$.

\section{Real-time polymerase chain reaction (RT-PCR)}

RT-PCR analyses were performed with an ABI 7900HT apparatus (Applied Biosystems; Norwalk, CT, USA), using RNA samples as template. Dissociation curves were constructed to test amplification validity. Target genes were obtained from NCBI (ncbi.nlm.nih.gov/). Database accession numbers and corresponding primer sets in RTPCR are as listed in Miao et al. [24]. actin was used as control gene. Relative gene expression was calculated by $2^{-\triangle \triangle C T}$ (cycle threshold) method using Sequence Detection software program v1.2.2 (Applied Biosystems). Each RT-PCR analysis was run in triplicate or quadruplicate to test consistency.

Transcriptome analysis.

JCM9042 and MK19 were grown in synthetic medium for $48 \mathrm{~h}$ at 21 or $28{ }^{\circ} \mathrm{C}$. Subsequent procedures for RNA sequencing were conducted by Majorbio BioPharm Technology (Shanghai). Clean data were de novo assembled by Trinity software program (github. com/trinityrnaseq/trinityrnaseq/wiki). Genes with fold changes $>1.5$-fold were functionally classified using the Munich Information Center for Protein Sequences (MIPS) FunCat. Processed data were deposited in NCBI Sequence Read Archive (SRA) under accession number SUB7646115.
Transmission electron microscopy (TEM) of cell surface Samples were cultured and collected under the same conditions as for RNA-Seq samples, fixed in $2 \%$ glutaraldehyde for $2 \mathrm{~h}$, then subjected for $1.5 \mathrm{~h}$ to second fixation with $1.5 \%$ potassium permanganate solution, rinsed twice (7 min each time) with PIPES 0.1 M, washed by ethanol gradient $(30,50,70,85,95 \%)$ elution, washed three times (10 min each time) with $100 \%$ ethanol, soaked in acetone/ Spurr resin (ratios 3:1, 1:1,1:3; 2 h each time), and embedded overnight in Spurr resin. Images were recorded by TEM using a Tecnai G2 Spirit Twin microscope (FEI) at acceleration voltage $120 \mathrm{kV}$.

\section{Statistical analysis}

Student's $t$-test was performed using SPSS (Statistical Program for Social Sciences) software program.

\section{Abbreviations \\ hmgr: 3-hydroxy-3-methylglutaryl-CoA reductase; hmgs: 3-hydroxy-3-methyl- glutaryl-CoA synthase; crtE: GGPP synthase; crtl: Phytoenedehydrogenase; pbs: Phytoene- $\beta$-carotene synthase; ast: Astaxanthin synthase; idi: IDP isomerase; mvk: Mevalonate kinase; mpd: Mevalonatepyrophosphate decarboxylase; fps: FPP synthase; acc: Acetyl-CoA carboxylase; sqs: Squalene synthase.}

\section{Acknowledgements}

The authors are grateful to Dr. S. Anderson for English editing of the manuscript.

\section{Authors' contributions}

$Y L$ and $L M$ designed and coordinated the project. $L M$ and SC performed

Q-PCR and measurement of astaxanthin and total ergosterol. LM, YL, ZL, and GG provided critical discussion and wrote the first draft. All authors read and approved the final manuscript.

\section{Funding}

This study was supported in part by Grant No. 31400037 from the National Natural Science Foundation of China.

\section{Availability of data and materials}

The transcriptional data was deposited to the NCBI Sequence Read Archive (SRA), other datasets and strains generated from present study are available from the corresponding author on a reasonable request.

Ethics approval and consent to participate

Not applicable.

Consent for publication

Not applicable.

Competing interests

The authors declare no competing interests.

Author details

${ }^{1}$ State Key Laboratory of Microbial Resources, Institute of Microbiology, Chinese Academy of Sciences, Beijing 100101, People's Republic of China. ${ }^{2}$ State Key Laboratories for Agro-biotechnology and College of Biological Sciences, China Agricultural University, Beijing 100193, People's Republic of China.

Received: 27 July 2020 Accepted: 19 November 2020

Published online: 07 January 2021 


\section{References}

1. Fassett RG, Coombes JS. Astaxanthin, oxidative stress, inflammation and cardiovascular disease. Future Cardiol. 2009;5(4):333-42.

2. Satoh A, Tsuji S, Okada Y, Murakami N, Urami M, Nakagawa K, Ishikura M, Katagiri M, Koga Y, Shirasawa T. Preliminary clinical evaluation of toxicity and efficacy of a new Astaxanthin-rich Haematococcus pluvialis extract. $J$ Clin Biochem Nutr. 2009:44(3):280-4.

3. Tripathi DN, Jena GB. Intervention of astaxanthin against cyclophosphamide-induced oxidative stress and DNA damage: a study in mice. Chem Biol Interact. 2009;180(3):398-406.

4. Camera E, Mastrofrancesco A, Fabbri C, Daubrawa F, Picardo M, Sies H, Stahl W. Astaxanthin, canthaxanthin and beta-carotene differently affect UVA-induced oxidative damage and expression of oxidative stressresponsive enzymes. Exp Dermatol. 2009;18(3):222-31.

5. Liu X, Osawa T. Astaxanthin protects neuronal cells against oxidative damage and is a potent candidate for brain food. Forum of Nutrition. 2009;61:129-35.

6. Nishigaki I, Rajendran P, Venugopal R, Ekambaram G, Sakthisekaran D, Nishigaki Y. Cytoprotective role of astaxanthin against glycated protein/ iron chelate-induced toxicity in human umbilical vein endothelial cells. Phytother Res. 2010;24(1):54-9.

7. Will OH 3rd, Sawtelle DE, Iverson P, Jorve K. Protection of Ustilago violacea from toluidine blue photosensitization and hydrogen peroxide induced killing and mitotic recombination by carotenes. Photochem Photobiol. 1988;48(3):305-9.

8. Wolf AM, Asoh S, Hiranuma H, Ohsawa I, lio K, Satou A, Ishikura M, Ohta S. Astaxanthin protects mitochondrial redox state and functional integrity against oxidative stress. J Nutr Biochem. 2010;21(5):381-9.

9. Johnson EA, Villa TG, Lewis MJ. Phaffia rhodozyma as an astaxanthin source in salmonid diets. Aquaculture. 1980;20(2):123-34.

10. Ke Y, Bu S, Ma H, Gao L, Cai Y, Zhang Y, Zhou W. Preventive and Therapeutic Effects of Astaxanthin on Depressive-Like Behaviors in High-Fat Diet and Streptozotocin-Treated Rats. Front Pharmacol. 2020;10:1621. https:// doi.org/10.3389/fphar.2019.01621.

11. Li MY, Gao CS, Du XY, Zhao L, Niu XT, Wang GQ, Zhang DM. Effect of subchronic exposure to selenium and astaxanthin on Channa argus, Bioaccumulation, oxidative stress and inflammatory response. Chemosphere. 2020;244:125546. https://doi.org/10.1016/j.chemosphere.2019.125546.

12. Benlarbi-Ben Khedher M, Hajri K, Dellaa A, Baccouche B, Hammoum I, Boudhrioua-Mihoubi N, Dhifi W, Ben Chaouacha-Chekir R. Astaxanthin inhibits aldose reductase activity in Psammomys obesus, a model of type 2 diabetes and diabetic retinopathy. Food Sci Nutr. 2019:7(12):3979-85. https://doi.org/10.1002/fsn3.1259.

13. Johnson EA. Phaffia rhodozyma, colorful odyssey. Int Microbiol. 2003;6(3):169-74.

14. Johnson EA, Lewis MJ. Astaxanthin formation by the yeast Phaffia rhodozyma. Microbiology. 1979;115:173-83.

15. Ramirez J, Gutierrez H, Gschaedler A. Optimization of astaxanthin production by Phaffia rhodozyma through factorial design and response surface methodology. J Biotechnol. 2001;88(3):259-68.

16. Visser $\mathrm{H}$, van Ooyen AJ, Verdoes JC. Metabolic engineering of the astaxanthin-biosynthetic pathway of Xanthophyllomyces dendrorhous. FEMS Yeast Res. 2003:4(3):221-31.

17. Merkulov S, van Assema F, Springer J, Fernandez Del Carmen A, Mooibroek $\mathrm{H}$. Cloning and characterization of the Yarrowia lipolytica squalene synthase (SQS1) gene and functional complementation of the Saccharomyces cerevisiae erg9 mutation. Yeast. 2000;16(3):197-206.

18. Sieiro C, Poza M, de Miguel T, Villa TG. Genetic basis of microbial carotenogenesis. Int Microbiol. 2003;6(1):11-6.

19. Verdoes JC, Krubasik KP, Sandmann G, van Ooyen AJ. Isolation and functional characterisation of a novel type of carotenoid biosynthetic gene from Xanthophyllomyces dendrorhous. Mol Genet Genomics. 1999;262(3):453-61.

20. Verdoes JC, Misawa N, van Ooyen AJ. Cloning and characterization of the astaxanthin biosynthetic gene encoding phytoene desaturase of Xanthophyllomyces dendrorhous. Biotechnol Bioeng. 1999;63(6):750-5.

21. Alvarez V, Rodriguez-Saiz M, de la Fuente JL, Gudina EJ, Godio RP, Martin JF, Barredo JL. The crtS gene of Xanthophyllomyces dendrorhous encodes a novel cytochrome-P450 hydroxylase involved in the conversion of betacarotene into astaxanthin and other xanthophylls. Fungal Genet Biol. 2006;43(4):261-72.

22. Ojima K, Breitenbach J, Visser H, Setoguchi $Y$, Tabata K, Hoshino T, van den Berg J, Sandmann G. Cloning of the astaxanthin synthase gene from Xanthophyllomyces dendrorhous (Phaffia rhodozyma) and its assignment as a beta-carotene 3-hydroxylase/4-ketolase. Mol Genet Genomics. 2006;275(2):148-58

23. Miao L, Wang Y, Chi S, Yan J, Guan G, Hui B, Li Y. Reduction of fatty acid flux results in enhancement of astaxanthin synthesis in a mutant strain of Phaffia rhodozyma. J Ind Microbiol Biot. 2010;37(6):595-602.

24. Miao L, Chi S, Tang Y, Su Z, Yin T, Guan G, Li Y. Astaxanthin biosynthesis is enhanced by high carotenogenic gene expression and decrease of fatty acids and ergosterol in a Phaffia rhodozyma mutant strain. FEMS Yeast Res. 2011;11(2):192-201.

25. Miao L, Chi S, Wu MR, Liu ZP, Li Y. Deregulation of phytoene- $\beta$-carotene synthase results in derepression of astaxanthin synthesis at high glucose concentration in Phaffia rhodozyma astaxanthin-overproducing strain MK19. BMC Microbiol. 2019;19(1):,133. https://doi.org/10.1186/s1286 6-019-1507-6.

26. Chi S, He Y, Ren J, Su Q, Liu X, Chen Z, Li Y. Overexpression of a bifunctional enzyme, CrtS, enhances astaxanthin synthesis through two pathways in Phaffia rhodozyma. Microb Cell Fact. 2015;14:90-102.

27. Alcaíno J, Bravo N, Córdova P, Marcoleta AE, Contreras G, Barahona S, Sepúlveda D, Fernández-Lobato M, Baeza M, Cifuentes V. The involvement of Mig1 from Xanthophyllomyces dendrorhous in catabolic repression: An active mechanism contributing to the regulation of carotenoid production. PLoS One. 2016:11:9-33.

28. Córdova P, Alcaíno J, Bravo N, Barahona S, Sepúlveda D, FernándezLobato M, Baeza M, Cifuentes V. Regulation of carotenogenesis in the red yeast Xanthophyllomyces dendrorhous, the role of the transcriptional co-repressor complex Cyc8-Tup1 involved in catabolic repression. Microb Cell Fact. 2016;15:193-212.

29. Caspeta L, Chen Y, Ghiaci P, Feizi A, Buskov S, Hallström BM, Petranovic D, Nielsen J. Altered sterol composition renders yeast thermotolerant. Science. 2014;346(6205):75-8. https://doi.org/10.1126/science.1258137.

30. Dichtl K, Samantaray S, Wagener J. Cell wall integrity signalling in human pathogenic fungi. Cell Microbiol. 2016;18(9):1228-38. https://doi. org/10.1111/cmi.12612.

31. Kim H, Thak EJ, Yeon JY, Sohn MJ, Choo JH, Kim JY, Kang HA. Functional analysis of Mpk1-mediated cell wall integrity signaling pathway in the thermotolerant methylotrophic yeast Hansenula polymorpha. J Microbiol. 2018;56(1):72-82. https://doi.org/10.1007/s12275-018-7508-6.

32. Wang JJ, Li MQ, Zheng FY, Niu CT, Liu CF, Li Q, Sun JY. Cell wall polysaCcharides: before and after autolysis of brewer's yeast. World J Microbiol Biotechnol. 2018;34(9):137. https://doi.org/10.1007/s11274-018-2508-6.

33. Gardner RG, Hampton RY. A highly conserved signal controls degradation of 3-hydroxy-3-methylglutaryl-coenzyme A (HMG-CoA) reductase in eukaryotes. J Biol Chem. 1999;274(44):31671-8.

\section{Publisher's Note}

Springer Nature remains neutral with regard to jurisdictional claims in published maps and institutional affiliations. 